\title{
Role of moisture transport for Central American precipitation
}

\author{
Ana María Durán-Quesada ${ }^{1,2}$, Luis Gimeno ${ }^{3}$, and Jorge Amador ${ }^{1,2}$ \\ ${ }^{1}$ Department of Atmospheric, Oceanic and Planetary Physics, University of Costa Rica, San José, Costa Rica \\ ${ }^{2}$ Center for Geophysical Research, University of Costa Rica, San José, Costa Rica \\ ${ }^{3}$ Environmental Physics Laboratory, University of Vigo, Vigo, Spain
}

Correspondence to: Ana María Durán-Quesada (ana.duranquesada@ucr.ac.cr)

Received: 1 December 2016 - Discussion started: 6 December 2016

Accepted: 31 January 2017 - Published: 28 February 2017

\begin{abstract}
A climatology of moisture sources linked with Central American precipitation was computed based upon Lagrangian trajectories for the analysis period 1980-2013. The response of the annual cycle of precipitation in terms of moisture supply from the sources was analysed. Regional precipitation patterns are mostly driven by moisture transport from the Caribbean Sea (CS). Moisture supply from the eastern tropical Pacific (ETPac) and northern South America (NSA) exhibits a strong seasonal pattern but weaker compared to CS. The regional distribution of rainfall is largely influenced by a local signal associated with surface fluxes during the first part of the rainy season, whereas large-scale dynamics forces rainfall during the second part of the rainy season. The Caribbean Low Level Jet (CLLJ) and the Chocó Jet (CJ) are the main conveyors of regional moisture, being key to define the seasonality of large-scale forced rainfall. Therefore, interannual variability of rainfall is highly dependent of the regional LLJs to the atmospheric variability modes. The El Niño-Southern Oscillation (ENSO) was found to be the dominant mode affecting moisture supply for Central American precipitation via the modulation of regional phenomena. Evaporative sources show opposite anomaly patterns during warm and cold ENSO phases, as a result of the strengthening and weakening, respectively, of the CLLJ during the summer months. Trends in both moisture supply and precipitation over the last three decades were computed, results suggest that precipitation trends are not homogeneous for Central America. Trends in moisture supply from the sources identified show a marked north-south seesaw, with an increasing supply from the CS Sea to northern Central America. Long-term trends in moisture supply are larger for the transition months (March and October). This might have important implications given that any changes in the conditions seen during the transition to the rainy season may induce stronger precipitation trends.
\end{abstract}

\section{Introduction}

Central America consists of a relatively thin strip of land surrounded by three large warm-water bodies, namely the Caribbean Sea, the easternmost tropical Pacific (ETPac), and the Gulf of Mexico (GoM). The region is known to be highly vulnerable to droughts, floods and associated landslides. A high percentage of the disasters related to natural phenomena reported in the area are linked to hydrometeorological events (Alfaro et al., 2014), which produce significant economic losses, as well as human casualties. Socio-economic development in the region is somewhat constrained by the annual cycle of rainfall, given that agriculture is one of the main economic drivers. Any improvement in terms of regional weather forecasting remains elusive as long as knowledge of regional precipitation and its sources is limited. The overall effect of major tropical disturbances on regional patterns of precipitation lacks scientific understanding, and this too affects the accuracy of forecasting. The role of the IntraAmericas Sea (IAS) in the relevant tropic-midlatitude interaction and feedback processes also requires further investigation (Douville et al., 2011). In very broad terms, the regional weather and climate are influenced by large sources of latent 
heat, strong easterly winds, the North Atlantic Subtropical High (NASH), high sea surface temperatures (SSTs), and intense precipitation (Wang, 2007). Regional terrain, including topography and diverse vegetation, which is found to be of importance (Lachniet et al., 2007), is still not properly represented in numerical simulations. The horizontal "seesaw" observed in Central American precipitation is often attributed to the effect of the continental divide. Drier conditions in northern Central America and the Pacific slope are in contrast with a wetter Caribbean side. The annual cycle of precipitation is characterised by a bimodal distribution that exhibits a minimum in July-August and maximum values in June and September-October. This bimodal distribution of precipitation, known as midsummer drought (MSD; after Magaña et al., 1999), is more marked on the Pacific side. On the Caribbean slope, heavy precipitation is observed during May and June, followed by a drastic reduction in late June, leading to a drier and less cloudy July-August (Taylor and Alfaro, 2005). Several authors have pointed to the seasonal migration of the Intertropical Convergence Zone (ITCZ), deep convection, low-level moisture transport, cyclone activity, and mid-latitude air intrusions as being the main drivers of regional precipitation (Schulz et al., 1997; Amador et al., 2006; Durán-Quesada et al., 2010; among others). Studies on the effect of large-scale structures such as the ITCZ on regional precipitation are scarce (Hidalgo et al., 2015), and some important interactions, including links with the tropical Pacific, are not fully understood. The region is influenced by deep convection and highly active stratiform precipitation. A large deep convective core is located over the Panama Bight (Zuluaga and Houze Jr., 2015), with an extended area of stratiform precipitation that becomes relevant for overall rainfall. The effect of mid-latitude interactions is known to be mostly related to the occurrence of rainfall during the dry period on the Pacific slope between November and February (Zárate, 2013; Sáenz and Durán-Quesada, 2015; Moron et al., 2016).

Previous works by the authors using global (DuránQuesada et al., 2010) and limited domain (Durán-Quesada, 2012) trajectories identified the sources of moisture linked to Central American precipitation. Their results highlighted the role of the Caribbean as the main source of moisture and the relevance of the Caribbean Low Level Jet (Amador, 1998, 2008) as a regional moisture conveyor. Wang et al. (2013) analysed the moisture transport from the Caribbean to the $\mathrm{Pa}$ cific across the Americas, highlighting the CLLJ as an interbasin moisture transport mechanism. These results, together with those of several authors, including Xu et al. (2005), Leduc et al. (2007), and Richter and Xie (2010), show coherence on the relevance of moisture transport from the Caribbean Sea. However, other regional moisture suppliers are poorly understood and the key processes that drive Central American precipitation remain unclear. The importance of other structures, including the Chocó Jet (CJ), has mainly been considered in terms of interannual variability modes (Poveda and Mesa, 2000) and mesoscale convective systems
(MCSs; Zuluaga Arias and Poveda Jaramillo, 2004). The response of regional precipitation to moisture supply from evaporative sources at different timescales has not yet been fully addressed. The connectivity between moisture transport from northern South America (NSA) to Central America also requires further consideration. Moreover, long-term trends in moisture supply and their effect on detected precipitation and low-level wind trends have never been documented for the Central American case.

This study is devoted to the long-term analysis of the importance of moisture supply to Central American precipitation, from the annual cycle to some aspects of interannual variability. Moisture transport controlled by regional LLJs is analysed to better explain the transport of moisture at intraseasonal scales and to study the modulation of these scales by interannual modes of atmospheric variability (i.e. El Niño-Southern Oscillation, ENSO). Trends in significant precipitation and moisture supply are analysed in order to assess consistency among precipitation trends and detected tendencies in terms of moisture supply. The remainder of the paper is organised as follows. Sect. 2 provides information on the methods and data used. The analysis of moisture supply for Central American precipitation from the identified sources is presented from a climatological perspective in Sect. 3. The annual cycle of moisture supply to Central American precipitation is then discussed further in Sect. 4. Section 5 emphasises the response of precipitation to moisture supply under ENSO conditions. An analysis of moisture supply and long-term trends in precipitation is given in Sect. 6, and some concluding remarks are presented in Sect. 7.

\section{Data and methodology}

In the present study the identification of moisture sources is based on the source-receptor relationship of the hydrological cycle. A Lagrangian numerical water vapour tracer approach was implemented. Considering that the region is characterised by intense rainfall and high rates of evaporation, we used the method developed by Stohl and James (2004), because unlike other methods it provides a diagnostic of the net freshwater flux $(E-P)$ rather than of evaporation $(E)$ alone (Gimeno et al., 2012). Global Lagrangian backward trajectories were generated using the Lagrangian particle dispersion model FLEXPART version 8 (Eckhardt et al., 2008) initialised with ERA-Interim Reanalysis data (Dee et al., 2011) using a $0.75^{\circ}$ horizontal resolution with water vapour as a tracer. Input data consisted of analyses every $6 \mathrm{~h}(00: 00$, 06:00, 12:00 and 18:00 UTC) with 3-hourly forecasts for intermediate times (03:00, 09:00, 15:00, 21:00 UTC). Ten-day Lagrangian backward trajectories were generated in a global domain for a total of $2.5 \times 10^{6}$ particles uniformly distributed within it, with each receiving the same mass. The accuracy of the method used to detect precipitation was assessed for 
Costa Rica by comparing rainy days detected from the trajectories with rainy days based on TRMM (Tropical Rainfall Measuring Mission; Huffman et al., 2007) and rain gauges located across the country. The trajectories method captured up to $86 \%(82 \%)$ of rainy days for the analysis domain detected by TRMM (rain gauges) over the period 2007-2012. Notice that for the Central Valley area, the matching of rainy days between the used rain gauges and TRMM is on average $90 \%$. Accuracy of TRMM rainfall amount estimates for Central America deserves validation; however, this is not the focus of the present work. Following the $E$ (evaporation) and $P$ (precipitation) diagnostics approach of Stohl and James (2004), precipitating air masses over the Central American region (defined as a polygon following the Central American borders) were tracked backwards in time for 10 days. The net fresh water flux was estimated for daily aggregates, with daily information averaged on a monthly basis to obtain the 1980-2013 climatology. Notice that in $(E-P)^{-10}$ the minus sign means backwards and the number 10 represents the number of days for which the air particles were tracked. Moisture exports from the identified evaporative sources to Central America were quantified to generate long-term time series of moisture export. The same procedure was applied on a country basis as the results will be also discussed from the country-wide perspective. Notice that consistency between the results for the Central America polygon and the integration of country polygons was evaluated. Internal variations were evaluated using noise-signal detection analysis, the results indicated there were no statistically significant internal variations.

A set of indices was used to evaluate the relationship between the contribution of the moisture sources to Central American precipitation and regional mechanisms. To quantify the intensity of the regional low-level jets, a CLLJ index was computed as the $925 \mathrm{hPa}$ zonal wind averaged in the region $12.5-17.5^{\circ} \mathrm{N}, 80-70^{\circ} \mathrm{W}$, based on previous work by Amador $(1998,2008)$ and Amador et al. (2006), and similar to that defined by Wang (2007). A CJ index was calculated as the $925 \mathrm{hPa}$ zonal wind averaged for the region of $5^{\circ} \mathrm{S}-7.5^{\circ} \mathrm{N}, 80^{\circ} \mathrm{W}$, following the definition of Poveda and Mesa (2000). Outgoing longwave radiation (OLR) from Chelliah and Arkin (1992) was averaged for five regions to represent an estimate of convection over the north, northwest, central, southwest, and southeast Amazon following a similar selection of area to Marengo et al. (2001). OLR was also averaged for an additional region over the easternmost location of the ITCZ. High-resolution precipitation data for Central America were obtained from the Climate Hazard Group InfraRed Precipitation with Station data archive (CHIRPS; Funk et al., 2015). Additional information used includes evapotranspiration from MODIS (Moderate Resolution Imaging Spectroradiometer; Mu et al., 2007) for 20002010 and the multivariate ENSO index (MEI; Wolter and Timlin, 1998).

\section{Results and discussion}

\subsection{Moisture supply and rainfall: behaviour and relevance of Central American precipitation moisture sources}

Durán-Quesada et al. (2010) diagnosed the moisture sources for Central American precipitation based on ERA-40 and FLEXPART computed trajectories from 2000 to 2004, reporting the Caribbean Sea as the main moisture source with a secondary contribution from the southern portion of the ETPac. Due to the short time span analysed, the authors of this study were unable to reveal any further information either on the climatology of the evaporative moisture sources linked to regional precipitation or on regional moisture transport and its variability.

Despite the Caribbean Sea (CS) being a continuous supply of moisture, moisture transport presents seasonality featured by the horizontal extent of the source. The CS extends from the Central American east coast to the southeastern Caribbean with a consistently strong intensity in terms of moisture supply between December and May along the Central American eastern coast (see Fig. 1a and b). The maximum intensity of the CS source shifts to the east as the Caribbean SST increases (see Fig. 1c). Moisture exports from the CS reach up to $10 \mathrm{~mm} \mathrm{day}^{-1}$ except during September-October-November (SON), when the maximum supply decreases to $5 \mathrm{~mm}$ day. It is noticeable that the diminishing of the CS as a source during SON is accompanied by a reduction in the easterly flow (see black vectors in Fig. 1c). During these months, the Western Hemisphere Warm Pool (WHWP; Wang and Enfield, 2001) develops its Pacific component, the Caribbean SST falls, and moisture is largely dragged by the cyclonic systems that develop in the Atlantic-Caribbean. The arrival of moisture exports from the CS to Central America is limited to long-range transport and by a reduction in moisture availability. Moisture transport from the GoM to the region becomes noticeable from late September to February, even though the contribution is much smaller than that from the CS. As the relevance of the GoM as a moisture source for the region is constrained by mid-latitude interactions. This source acquires importance in association with winter circulation patterns related to cold surges, which have been found to contribute to the precipitation over Central America during a relatively dry period (Sáenz and Durán-Quesada, 2015).

Moisture supply from the ETPac starts to develop in late May and reaches a maximum intensity between August and September (Fig. 1c). The ETPac source is located in a region characterised by strong evaporation (Amador et al., 2006). Furthermore, the peak in its annual cycle is coherent with the maximum intensity of the CJ (Poveda and Mesa, 2000). As the easterly flow decreases and the CJ intensifies, moisture supply from the ETPac is enhanced (Fig. 1d). This behaviour highlights the interplay between the CLLJ and the 
(a) DJF

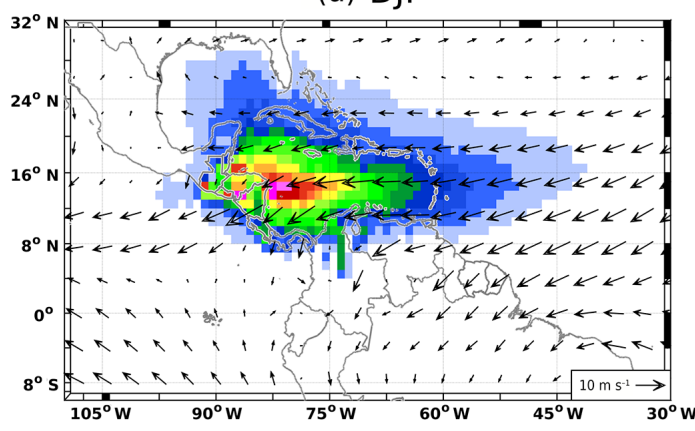

(c) JJA

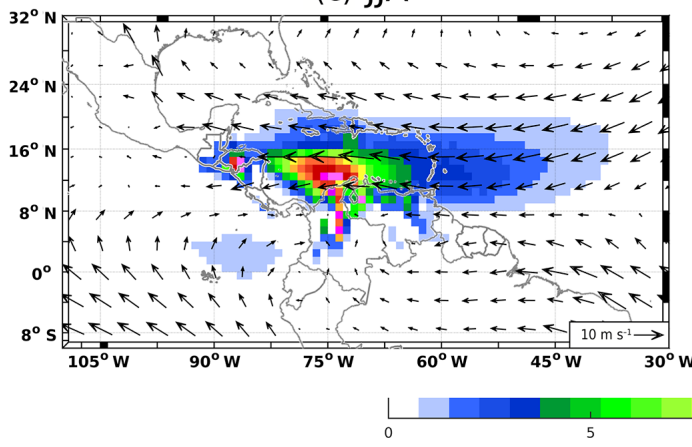

(b) MAM

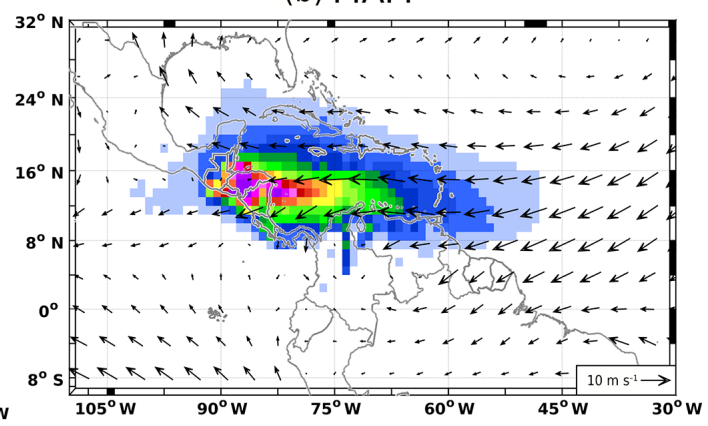

(d) SON

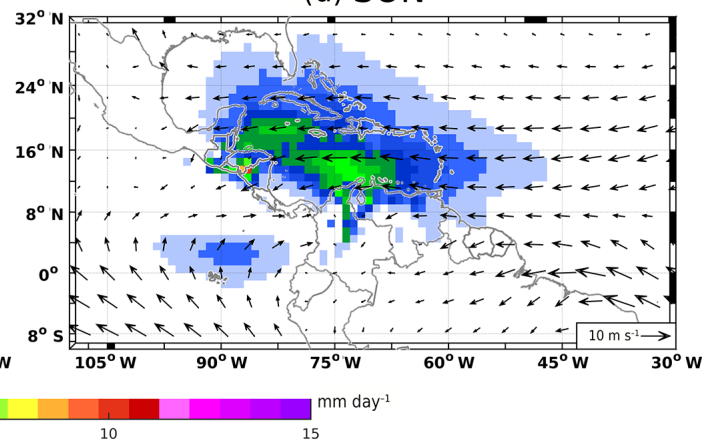

Figure 1. Positive $(E-P)^{-10}$ seasonal climatology for 1980-2013 (shaded contours) and $925 \mathrm{hPa}$ winds from ERA-Interim. Coloured areas show the presence of an evaporative source of moisture linked with precipitation over Central America. The high intensity of the Caribbean Sea as a source of moisture is observed all year round while the contributions of the eastern tropical Pacific and the GoM are strongly seasonally constrained. Wind vectors indicate the boundary between the oceanic sources of moisture identified for Central America and the regional low-level jets, CLLJ and CJ.

$\mathrm{CJ}$ in regional moisture transport. In addition, the intensity of the deep convection in the ETPac provides a suitable environment for the release of latent heat and enhanced surface evaporation. The latter may lead to an increase in moisture availability related to the ETPac source. Moreover, contributions from the ETPac source are also forced by large-scale processes including ITCZ movements, shallow meridional circulation in the region (Zhang et al., 2004), and the development of deep convection.

The identification of moisture sources suggests that northern South America represents a remote supply of moisture for Central American precipitation. The Orinoco River basin is found to be an evaporative source with an annual cycle similar to that of the CS. The Magdalena River basin is identified to play an important role in long-range continental moisture exports to Central America. In this case, the moisture supply is stronger in June-July-August (JJA). It is worth noting that the Magdalena and Orinoco river basins are also the principal moisture sinks in northern South America (Meade, 2007; Poveda et al., 2001). Despite this, they provide a summertime contribution to Central American rainfall. The transport of moisture from these remote continental sources is constrained by regional convective activity and local precipitation.
Central America is itself an evaporative moisture source, as suggested by the large positive values of $(E-P)^{-10}$. The annual cycle is well defined and northern Central America is the primary destination of the source, the transport being stronger from December to early June. It is beyond the scope of this work to quantify the evapotranspiration; however, it is important to assess the consistency between this variable and the activity of the local moisture source. By comparing Figs. 1 and 2, it can be seen that the strong seasonal signal of evapotranspiration from MODIS is coherent with the seasonal characteristics of the identified supply of moisture from Central America. A maximum evapotranspiration for the area of Bosawás Natural Preserve (Nicaragua) Patuca National Park, and Río Plátano Biological Preserve in Honduras is exhibited for March-April-May (MAM). Other areas with significant evapotranspiration are El Mirador National Park, Sierra Del Lacandón National Park, and Biosfera Maya Biological Preserve in Guatemala, as well as Calakmul Biosphere Preserve and Montes Azules National Park in Mexico. This finding is in good agreement with the highest positive value of $(E-P)^{-10}$ detected over northern Nicaragua, Honduras and the Yucatán Peninsula. Because evapotranspiration depends on plants (Brümmer et al., 2012), the highest values tend to be found in regions with dense vegetation. 

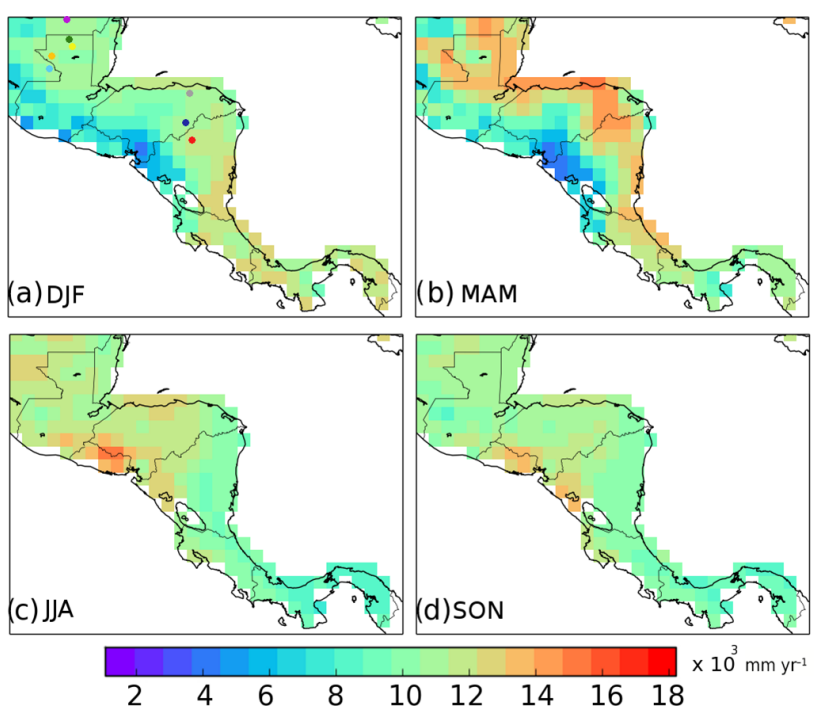

Figure 2. Seasonal average of MODIS-estimated evapotranspiration for 2000-2010. (a) DJF, (b) MAM, (c) JJA and (d) SON. Despite the coarse resolution, it can be seen that evapotranspiration presents a strong seasonality. Marked contrasts during the months containing the first peak of the rainy season are observed between the Caribbean and Pacific slopes. The latter is coherent with known higher precipitation and evaporation rates over the Caribbean slope compared to the Pacific influence. Locations of the natural parks is indicated as dots in (a) as follows: Patuca National Park (blue), Bosawás Natural Preserve (red), Río Pátano Biological Preserve (grey), El Mirador National Park (green), Sierra del Lacandón National Park (orange), Biosfera Maya Biological Preserve (yellow), Calakmul Biosphere Preserve (purple) and Montes Azules National park (sky blue).

Figure $1 \mathrm{~b}$ indicates that the region becomes a strong moisture supplier during the first rainy season (MAM), suggesting the regional importance of surface-precipitation feedback mechanisms. Smaller moisture contributions from the Pacific slope of Central America are consistent with the known horizontal precipitation "seesaw" between the Caribbean and Pacific sides of Central America. However, a more fundamental analysis is required to establish the link between local moisture supply and evapotranspiration, as well as to quantify moisture recycling and its direct relationship with rainfall.

\subsection{Annual cycle of moisture transport to Central American precipitation and the role of the LLJs}

Moisture transport from each identified evaporative moisture source was computed from the trajectories dataset, transport is reported in sverdrup units, $1 \mathrm{~Sv}=1$ million $\mathrm{m}^{3}$. The annual cycle of moisture transport from the CS, as shown in Fig. 3a, suggests a relatively constant moisture supply to Central America that decreases slightly between September and November, which is a period of intense development of tropical cyclones over the Atlantic Basin. More detailed anal- ysis allows us to determine that the overall moisture supply to Central America from the CS shows strong variations across Central America. In fact, computing the moisture transport for the Central American countries reveals significant differences in the annual cycle of moisture transport. Moisture transport from the CS to Belize and El Salvador is small $(0.2 \mathrm{~Sv})$, and nearly constant throughout the year, due in part to a marginal exposure to the moist air flow. Transport to Honduras, Guatemala and Nicaragua is consistent with the overall annual cycle depicted in Fig. 3a. The main difference is that moisture transport from this source is larger for Nicaragua (up to $1.5 \mathrm{~Sv}$ ) and is more intense from October to May compared with transport to Honduras and Guatemala. Transport from the Caribbean Sea to southernmost Central America shows a characteristic annual cycle characterised by a more intense moisture supply in December-JanuaryFebruary (DJF). It is worth noting that in summer the transport to Costa Rica and Panama decreases, while increasing for Honduras, Guatemala and Nicaragua at this time. Country estimates of CS moisture transport reflect the strong dependence it has on the position and intensity of the CLLJ.

Moisture supply from the ETPac to Central American precipitation is markedly bimodal, as shown in Fig. 3b. Even when this source is an order of magnitude smaller than the Caribbean supply, moisture transport from the ETPac still peaks during the months that characterise the transition to the rainy season. The July minimum is coherent with the intensification (decrease) in the easterly (westerly) flow and partly coincides with the presence of the MSD over the Pacific slope of Central America. Unlike the transport from the Caribbean, the bimodal moisture supply pattern is observed for the whole Central American region. Transport is greater to Panama, Nicaragua and Costa Rica, with the two last countries showing the strongest July minimum. The secondary peak of transport to Panama represents up to double the transport that occurs during May (not shown). The fingerprint of the transport of moisture from the GoM is also well defined, with transport increasing during October and continuously decreasing until it falls to a minimum after May (Fig. 3c). It can be seen that the interannual variability is relatively small and that extreme values shown as outliers (marks) are significant, showing much stronger transport. The fact that moisture supply from the GoM peaks during a period seeing the entry of mid-latitude systems is highlighted, because this provides information relevant to the links between mid-latitude interaction and rainfall during the dry season. It is also worth mentioning that even when moisture supply is mostly constrained to the northern portion of Central America, Nicaragua receives approximately $0.10 \mathrm{~Sv}$ when the source is active.

Local contributions are in broad coherence with the first part of the rainy season in the region (Fig. 3d). In agreement with the seasonal distribution of evapotranspiration according to MODIS estimates (not shown), Guatemala, Honduras and Nicaragua receive their largest supply from inland evap- 

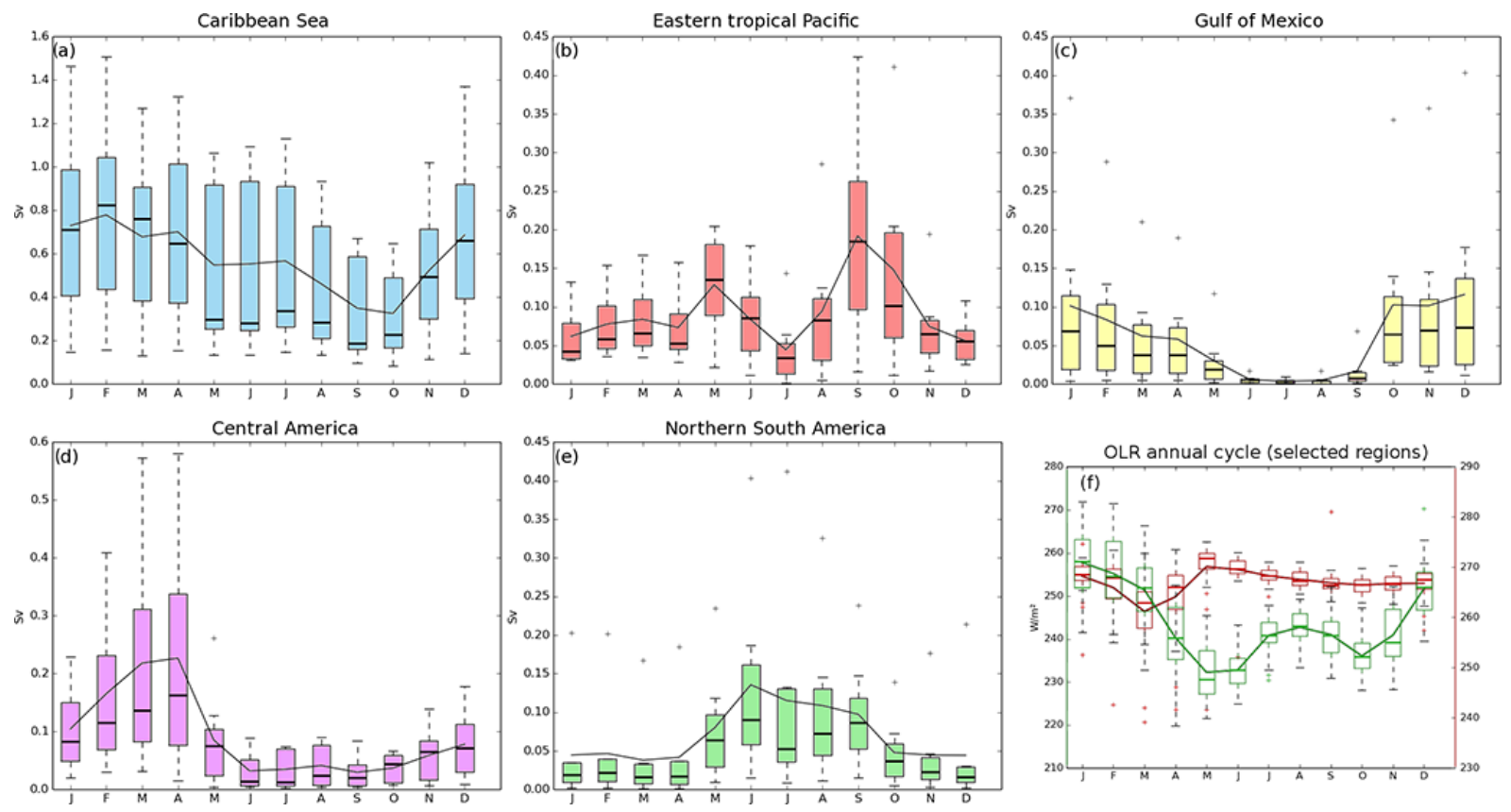

Figure 3. Box plots providing information on the annual cycle of moisture transport from the identified evaporative moisture sources to Central American precipitation, (a) Caribbean Sea, (b) ETPac, (c) GoM, (d) Central America and (e) northern South America (Orinoco and Magdalena river basins). (f) Annual cycle of OLR computed for the Amazon (green) and easternmost ITCZ (red) regions. The mean is shown as a black line, and the + marks, the narrow black line, and the lower and upper box limits represent outliers and the 50th, 25th and 75th percentiles respectively. Beyond the determined annual cycle, a general measure of interannual variability is also given by the spread. Note that the vertical scale is different for each panel.

orative sources, suggesting that moisture recycling could follow a similar annual cycle. This latter view may support the hypothesis of a difference between the first and second parts of the rainy season, which suggests that the second part is driven by large-scale dynamics rather than by the local processes that drive the first part of the rainy season. A rigorous quantification of moisture recycling in the region is key to assessing the role of local contributions to precipitation. This is not a simple matter because vegetation dynamics and temperature are both fundamental parts of the problem, and intensive changes in land use are well known in the region (Aide et al., 2013).

Transport from the remote evaporative source from the Orinoco and Magdalena river basins peaks in the summer months. It shows a moderate interannual variability and a strong influence of extremes (Fig. 3e). A more detailed country-level analysis reveals a slightly different latitudinal supply regime from this source. While a bimodal annual cycle of moisture supply is observed for Nicaragua and northern countries with maxima in June and September, a single summer peak is seen in the moisture contributions to Costa Rica and Panama. Furthermore, the moisture supply to Panama ( $\max 0.41 \mathrm{~Sv}$ ) is around twice as high as the transport to Costa Rica $(0.19 \mathrm{~Sv})$ and more intense than for the other countries. Supply from this remote source is relevant because it may help us to understand how northern South
American processes are connected with Central American rainfall distribution and are further linked with the Caribbean Sea dynamics. Moisture transport from this source is constrained by the availability of moisture, which implies that the supply is dependent on precipitation over the basin and on high evaporation rates. The marked seasonality of the moisture transport from this source is in good agreement with the known annual cycle of moisture sinks in northern South America. In the case of the Mapire River mouth, the precipitation follows a similar annual cycle to the moisture supply from northern South America. Precipitation from the Musinacio station, for example, exhibits a marked peak during June (see Fig. 2 in Dezzeo et al., 2003). At the same time, the Magdalena Valley experiences a relative minimum of precipitation, suggesting that in summer evaporation exceeds precipitation in the region, enhancing the atmospheric moisture. The moist air masses move to the northwest as a result of the strengthening of the easterly flow.

Regression of the evaporative sources against the CLLJ and $\mathrm{CJ}$ indices (Fig. 4a and b) shows the contrasting response of the two main oceanic sources to these LLJs. As the easterly flow increases, the development of the CLLJ favours transport from the CS, while transport from the ETPac is largely inhibited (Fig. 4a). The opposite is observed for the CJ (Fig. 4b). The strong link between the arrival of moisture from the oceanic sources and the LLJs shows the importance 


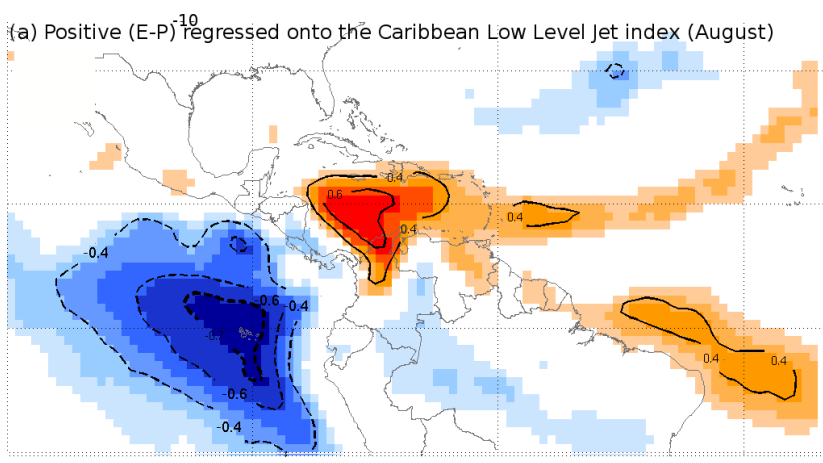

(b)Positive (E-P) ${ }^{-10}$ regressed onto the Chocó jet index (August)

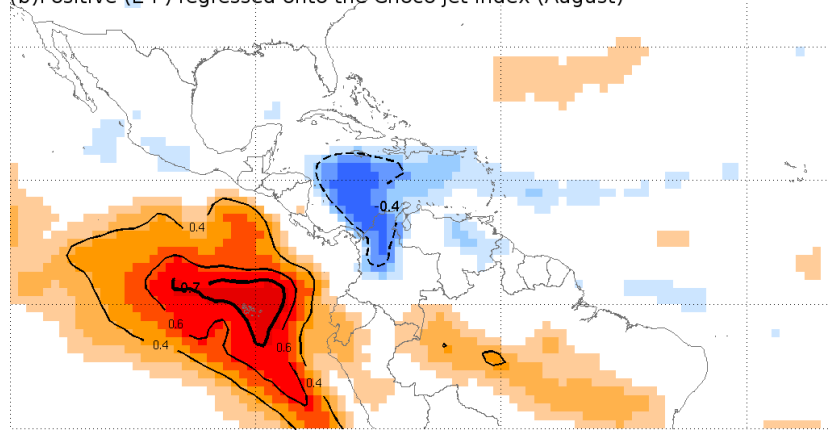

Figure 4. Positive $(E-P)^{-10}$ regressed against the CLLJ index (upper panel) and the CJ index (lower panel) for August. Only significant values are shaded and contours are indicated for correlations larger than 0.4. Blue shading in the upper panel shows a strong negative correlation between the CLLJ and the ETPac sources but a positive correlation with the Caribbean Sea source. The lower panel shows the opposite, highlighting a large positive correlation between the activity of the moisture supply from the ETPac source and the CJ index.

of these structures to the regional distribution of precipitation. It is worth noting that the CLLJ not only accounts for the dragging of moisture from the Caribbean but is also able to modulate moisture transport from the tropical Atlantic and northern South America into the mid-latitudes of both hemispheres. Here again, moisture contributions from northern South America depend on both regional and large-scale processes. On the one hand, the interplay between the Orinoco and Magdalena river basins as sinks for Amazon moisture implies a moisture availability for Central American precipitation constrained by Amazon convection. Indeed, moisture supply from northern South America increases with Amazon convection, as suggested by the minimum OLR values for selected regions over the Amazon (Fig. 3f). Convection over the Amazon enhances evapotranspiration processes in the region and provides moisture to the Magdalena and Orinoco basins. Moisture held by the atmosphere is available to be transported and in the presence of an efficient conveyor (e.g. the CLLJ) it is then transported to Central America. The intensification of moisture transport from this source between May and September is in agreement with the reduction in rainfall for several locations in northern Colombia (Poveda et al., 2005). Recent studies make this northern South AmericaCentral America link clear; Arias et al. (2015) showed that La Niña enhances the moisture transport to northern South America hence decreasing availability for Central American supply.

Moisture supply from the ETPac relates to a low CLLJ intensity but also to the increase in the extent of the Pacific component of the WHWP. Large-scale convection also plays a role in the modulation of the ETPac moisture transport, which is inhibited by deep convection such as that related to the ITCZ. A large negative correlation between the OLR averaged for the easternmost part of the ITCZ and the ETPac moisture source was found to be most pronounced in summer-autumn (OLR annual cycle is shown in Fig. 3f). The identified mechanisms are largely related to the development of precipitation in the second part of the rainy season. The moisture supply that may enhance the first part of the rainy season in the region is not fully understood. The strong link between the distribution of precipitation and the activity of an evaporative source located over Central America suggests a relationship with surface conditions. It has been mentioned that evapotranspiration may play a key role in supplying moisture during the first part of the rainy season. This connection relates to the issue of vegetation-precipitation controls. Therefore, the quantification of evapotranspiration and some knowledge of the vegetation fraction would give new insights and scientific knowledge of the processes that dominate the first part of the rainy season at different timescales.

The interpretation of the relationship between moisture supply and rainfall over a defined region is often an issue. In this study, we aim to provide information of the relevance of the moisture supply for regional rainfall. Once the moisture sources were characterised, the moisture supply from each source was estimated using a Lagrangian approach. The correlation between time series of moisture supply and spatial CHIRPS rainfall estimates for the detected rainy days (90\% significance) was computed; results are summarised in Fig. 5. Moisture transport from the CS favours rainfall in northern Central America Caribbean slope early in the year (Fig. 5a). As observed from Fig. 5b, moisture transport has very little influence for the first rainy season. We propose that this rainy period is mostly forced by local processes, with surface fluxes playing a relevant role for the precipitation initiation (see also Fig. 5i); it can be observed that overall moisture supply from the continental region decreases during the first rainy season as very little moisture is available. For midsummer, CS transport (Fig. 5c) shows a remarkable result, while the CLLJ reaches its maximum contribution to the Caribbean slope of Costa Rica rainfall increases. Moreover, as the transport increases, Central American Pacific coast becomes drier. The area featured by negative correlation values (blue in Fig. 5c) is clearly identified as the Central American Dry Corridor (CADC). Here we highlight that fact that the intensification of moisture transport from the CS and associ- 

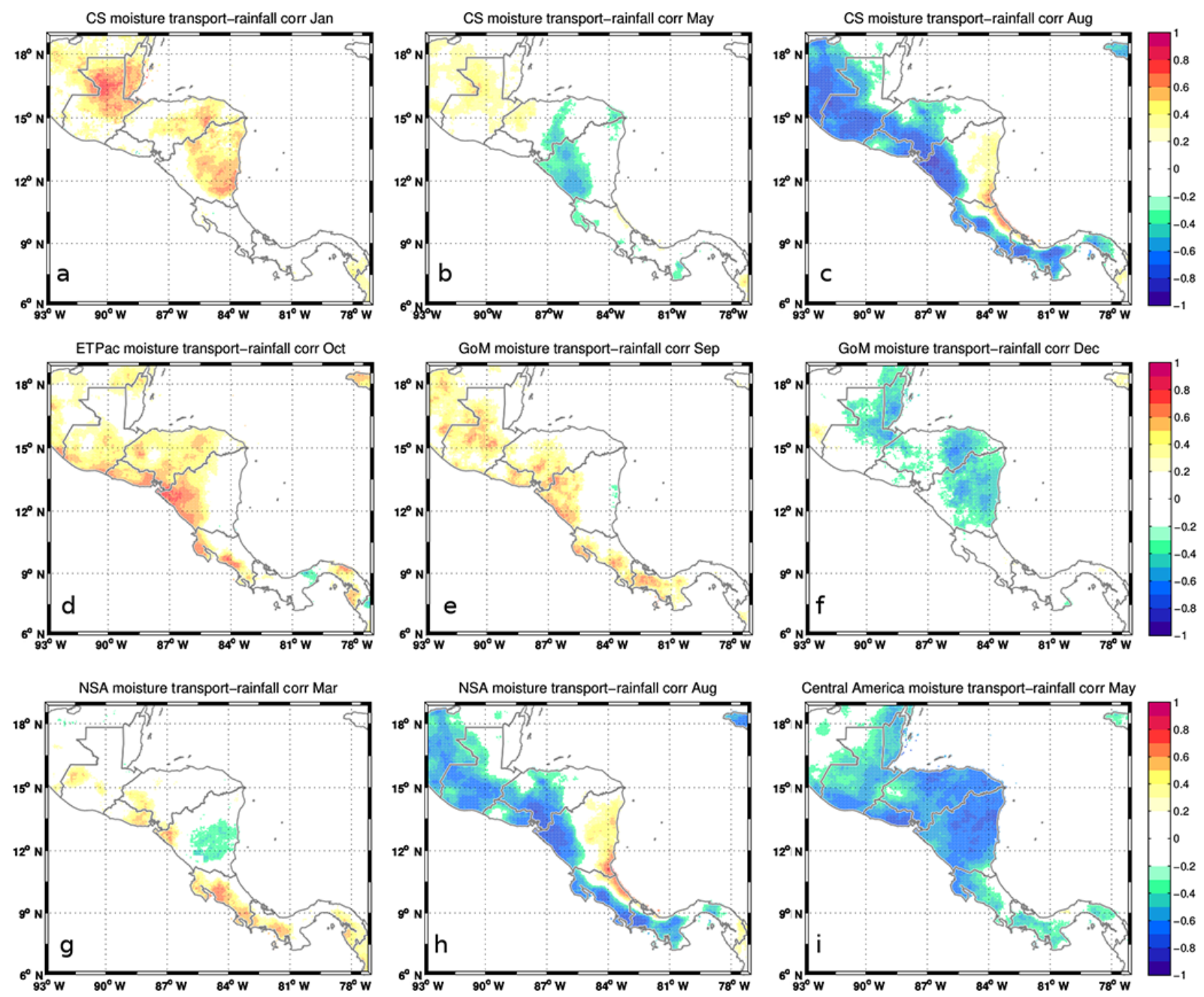

Figure 5. Spatial correlation of moisture transport from the identified sources and CHIRPS rainfall for the 1981-2013 period. Only correlation coefficients larger than \pm 0.2 and significant at the $90 \%$ level are shown. Months for which the correlation patterns were more coherent were chosen. Positive correlation is to be interpret as how the net moisture supply contributes with rainfall, whereas negative values require a more careful interpretation. Notice that, for this case, the negative correlation values are more related with the moisture conveyor mechanism that with rainfall itself. Here negative values from (a) to (h) suggest that conditions featured by a reduced influence of the moisture mechanism is more likely to favour rainfall in the regions. Panel (i) has a different interpretation and relies on the fact that as moisture is evaporated from the continental region the amount of available moisture to contribute with rainfall decreases.

ated mechanisms play a major role in the establishment of the CADC. In contrast, as the CLLJ retreats (Fig. 5d) in autumn and the $\mathrm{CJ}$ is intensified, rainfall increases aided by the moisture supply from the now active ETPac source (Fig. 5). The modulation of the Pacific rainfall annual cycle, and therefore the depth of MSD, results from the interplay between the regional LLJs and of course its associated dynamics. The effect of the GoM moisture supply is small, still, its influence might contribute to reduce the impact of the MSD period rain deficit (Fig. 5e). Transport from northern South America accounts as mentioned before, mainly for southern Central America (Fig. 5g). However, its relevance during summer time also hints to role of its moisture conveyor, the CLLJ, to be key for the distribution that features the CADC and is shown by the drying linked to the well-known MSD (Fig. 5h).

\subsection{Response of oceanic moisture sources to ENSO forcing}

The integrated positive net freshwater fluxes were composited for warm and cold ENSO events at a monthly timescale based on a $\pm 0.75^{\circ} \mathrm{C} \mathrm{SST}$ anomaly using the MEI. The base line period for the computation of the anomalies was 19812010. The results reveal a large deviation in the position and intensity of the evaporative moisture sources compared to neutral years. Figure 6 shows the warm-cold ENSO differences for positive $(E-P)^{-10}$ values, suggesting a large 

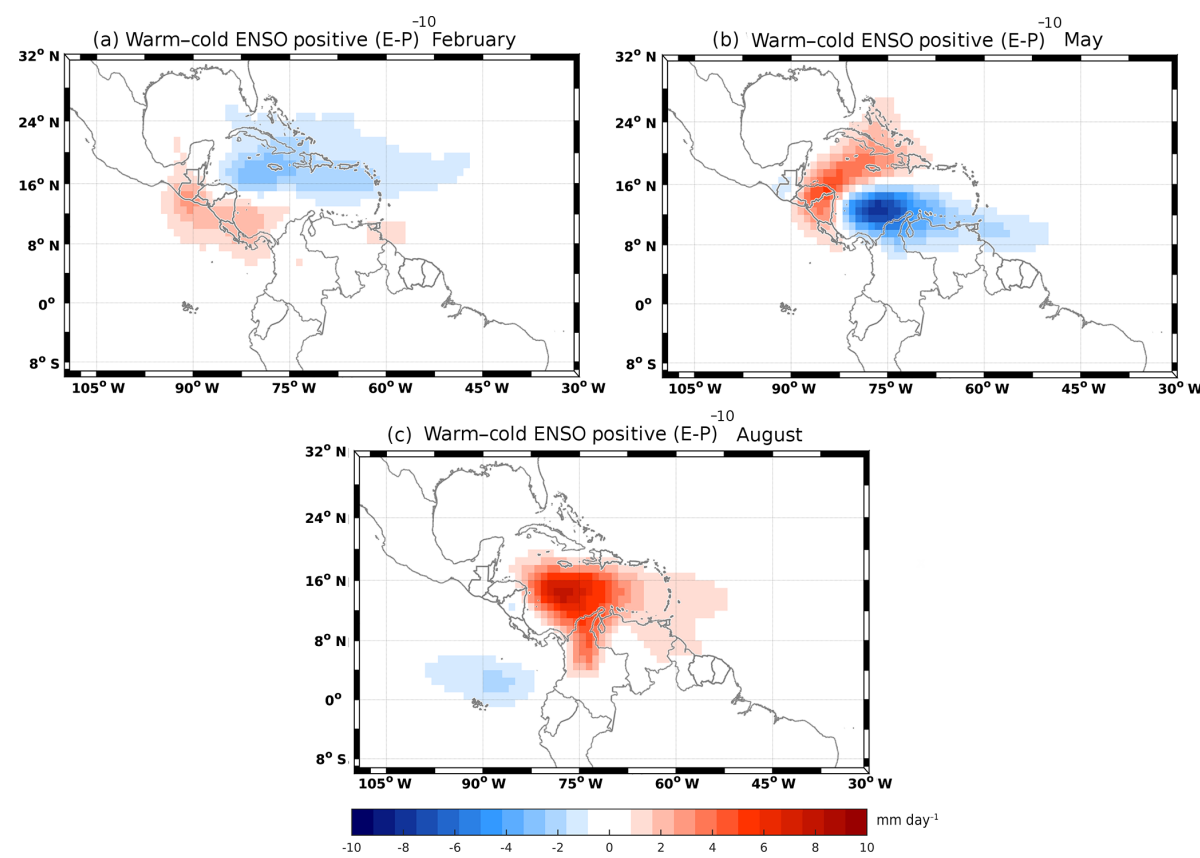

Figure 6. Positive $(E-P)^{-10}$ composite differences for warm and cold ENSO events based on a $\pm 0.75^{\circ} \mathrm{C} \mathrm{SST}$ anomaly for the MEI using the 1981-2010 base line for (a) February, (b) May and (c) August. Blue colours represent a decrease in the evaporative source of moisture for warm ENSO, while red colours represent the intensification of the evaporative moisture source under warm ENSO conditions.

variability in the supply from the oceanic moisture sources. During boreal winter, moisture supply from the Caribbean decreases, while inland and coastal Pacific $(E-P)^{-10}$ values increase slightly (Fig. 6a). The subsequent reduction in Caribbean moisture transport is attributed to the response of the deceleration of the CLLJ under warm ENSO conditions in winter time (Amador et al., 2006; Amador, 2008; Maldonado et al., 2015). Stronger differences are detected as the first rainy season starts, with a greatly reduced contribution from the southwest Caribbean as shown by the dark blue shading in Fig. 6b. In contrast, moisture supply from the northern Caribbean is enhanced for warm ENSO conditions, similar to the evaporative source observed over Nicaragua and Honduras (red shades in Fig. 6b). Under cold ENSO conditions, moisture supply from the Caribbean results in a dipole, from which the inhibition of moisture transport from the southern Caribbean becomes evident. A small reduction in the positive $(E-P)^{-10}$ values over the northern portion of the Orinoco River basin is also noted. In contrast, as the CLLJ strengthens and the warm ENSO causes the easterlies to accelerate, the Caribbean Sea moisture source is reinforced. The red shading in Fig. 6c over the Caribbean (and northern Colombia) suggests that a warm ENSO favours the intensification of moisture supply from this source, aided by the strengthening of the CLLJ. The increase in moisture transport from this source under El Niño conditions is consistent with the known surplus of precipitation on the Caribbean slope of Central America for a warm ENSO (Fig. 11 of Amador, 2008). The composite differences also show good agreement with the

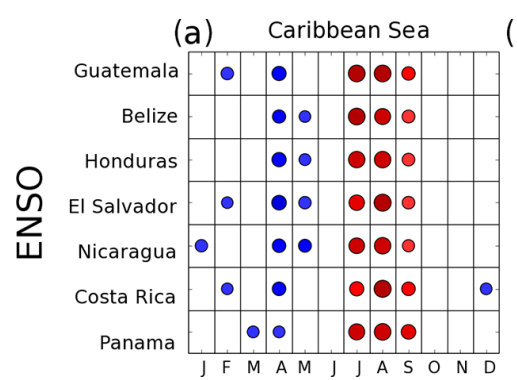

(b) Eastern tropical Pacific

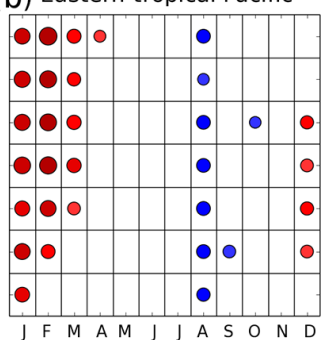

Figure 7. Correlation coefficients between moisture supply from the (a) Caribbean Sea and (b) the eastern tropical Pacific to precipitation in Central American countries and the MEI index. Only significant correlations are depicted; colour and circle size are proportional to correlation between -1 and 1 . Blue (red) indicates negative (positive) correlations.

proposed moisture conveyor mechanisms as the ETPac supply is reduced for warm ENSO in coherence with the weakening of the southwesterlies over the Pacific.

As a complementary analysis, the moisture supply from the evaporative sources was computed and the correlation between the moisture transport and the MEI was estimated. Results for the Caribbean and ETPac sources are shown in Fig. 7. The strongest response to ENSO is observed for moisture contributions from the Caribbean Sea (Fig. 7a) with a contrasting correlation pattern compared to the response of the ETPac moisture supply (Fig. 7b). In general, Central America experiences an increase (decrease) in moisture con- 
tributions from the Caribbean for warm (cold) ENSO during the transition to the first part of the rainy season. The summer response to ENSO is homogeneous for the Central American region. In contrast, the winter and spring response is heterogeneous, and the regional response becomes more consistent during the transition to the first part of the rainy season. For this period, the moisture supply exhibits a negative correlation, suggesting that the warm ENSO is linked with a reduction in moisture transport derived from a weakened moisture source in the central Caribbean (Fig. 6b). This finding is in good agreement with Maldonado and Alfaro (2012), who highlighted the intensification of dry conditions under warm ENSO. It is clear that the response of the moisture supply to ENSO is largely influenced by its effect on the CLLJ and the mean easterly flow, as shown by their identical ENSO response. However, it is important to note that moisture supply from the Caribbean is not driven by transport alone. In particular, under ENSO conditions energy fluxes become important over the Caribbean as a result of SST anomalies and advection of moisture to the atmosphere. Chikamoto and Tanimoto (2005) showed that specific humidity differences between the air and sea interfaces are related to asymmetric latent heat flux anomalies linked to ENSO activity. These authors also found that near-surface specific humidity anomalies dominate the difference in the air-sea humidity anomaly. Because the boundary layer humidity gradient depends on effective evaporation, it can be argued that both the boundary layer depth and the humidity are fundamental to the role of the Caribbean Sea as an evaporative moisture source (A. M. Durán-Quesada, personal communication, 2016). As a result of its intensification the CLLJ becomes not only a moisture conveyor structure but also a mechanism able to enhance evaporation by drag, increase the humidity gradient, and also generate surface cooling (Amador, 2008). The CLLJ response to ENSO therefore plays an even bigger role in the modulation of the moisture supply from the Caribbean. Its intensification under warm ENSO increases the moisture transport but also contributes to the increase in atmospheric moisture availability and atmospheric instability, especially in the central Caribbean.

From Fig. 7a, it is observed that a warm ENSO favours the intensification of a moisture source to the west of the Central American coast during the winter months. Compared with the climatological moisture supply from the ETPac, this winter contribution intensified by warm ENSO conditions has a different origin. The positive response of the ETPac moisture supply to a warm ENSO during winter (Fig. 7b) is not completely clear, however. A southward displacement of a weaker winter ITCZ, caused by changes in the tropical energy flux (Schneider et al., 2014), facilitates moisture transport by enhanced westerlies over the Pacific for warm ENSO. However, the location of the moisture source suggests that the origin of this moisture supply is not fully driven by the motion of the ITCZ. The increase in the contributions for warm ENSO is proposed to be linked to the effect of rain- producing systems. These systems can be associated with the penetration of cold surges, known to increase during El Niño events (Magaña et al., 2003) and to modify the regional distribution of precipitation (Sáenz and Durán-Quesada, 2015). During summer, the negative correlation between the moisture supply from the ETPac and the ENSO can be explained by an enhanced deep convection linked to the ITCZ for cold ENSO events as revealed by OLR composites (not shown).

\subsection{Trends in moisture supply from evaporative sources}

Central America is often referred to as a climate change hotspot, based on climate projections (Giorgi, 2006; Neelin et al., 2006; Rauscher et al., 2008, 2011; Diffenbaugh and Giogi, 2012; Imbach et al., 2015; Nakaewaga et al., 2014; Hidalgo et al., 2013). As most of those studies rely on modelling and projections approaches, here we aim to better understand how short-term trends relate with natural variability at different timescales. Temperature trends are consistent across many studies; precipitation trends have failed to show any sound significance. An example is given in the observational study of Aguilar et al. (2005), which shows a marked significant temperature trend and highlights the non-significance of any precipitation trends. Understanding trends in the hydrological cycle for the region is an important milestone in providing a solid basis for water management policies in the context of resources availability affected by the intensive exploitation of surface water reservoirs (Arias and Calvo-Alvarado, 2012). Considering the sensitivity of the region to extreme hydrometeorological events, it is imperative to identify any consistent significant trends towards drier or wetter conditions in order to support water resource management and mitigation and adaptation policies. Shortterm trends were detected for moisture supply to Central American precipitation using a modified Mann-Kendall test. The evaluation of these trends was carried out for the countries of interest in order to check for consistency with reported differences in north-south trends.

The strongest trends were detected for oceanic evaporative sources of moisture. A strong seasonal difference was identified for the Caribbean Sea source (Fig. 8a), while a consistent trend was reported for the ETPac source. Moisture supply from the CS was found to increase (decrease) by up to $10 \times 10^{-3} \mathrm{~Sv} \mathrm{yr}^{-1}$ during March (October). An increasing trend in moisture supply was found during transition months, with values of $1 \times 10^{-3} \mathrm{~Sv} \mathrm{yr}^{-1}$ for southern Central America, and $8 \times 10^{-3} \mathrm{~Sv} \mathrm{yr}^{-1}$ for Nicaragua and Honduras. According to the model results for October, Honduras and Guatemala have been experiencing a decrease in moisture contributions from the Caribbean Sea, with trends of $-7 \times 10^{-3}$ and $-10 \times 10^{-3} \mathrm{~Sv} \mathrm{yr}^{-1}$, respectively. In contrast, during late autumn Panama shows an increasing trend of $4 \times 10^{-3} \mathrm{~Sv} \mathrm{yr}^{-1}$. The results reveal an opposite response during the two rainy seasons for the trends in Honduras. This suggests a trend to wetter (drier) for the first (second) part 


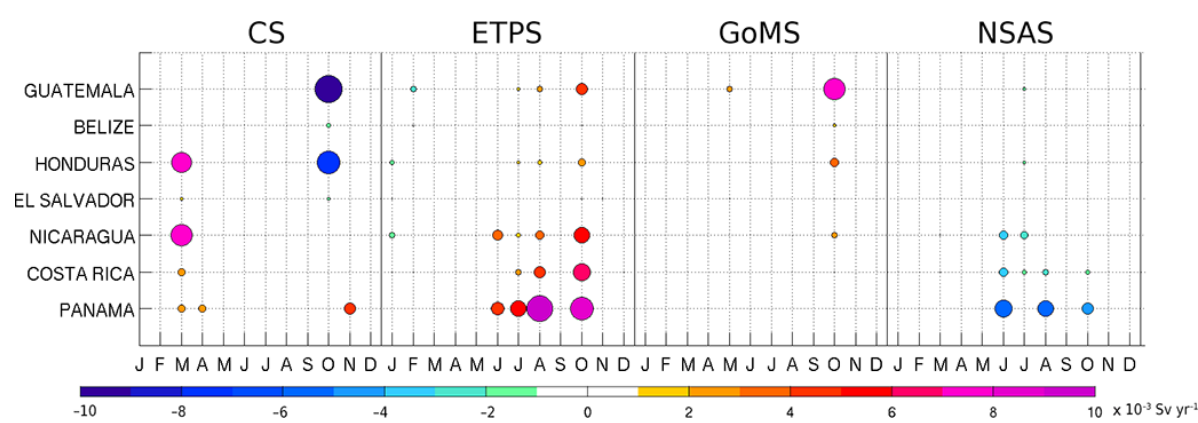

Figure 8. Long-term trends for moisture supply from the evaporative sources (a) Caribbean Sea, (b) eastern tropical Pacific, (c) GoM, and (d) northern South America. Note that the evaporative source located over Central America was not considered for this part of the analysis as we have no further details of the observed evapotranspiration trends at this stage in our research. Negative (positive) values represent decreasing (increasing) trends; only those with statistical significance at the $90 \%$ level were plotted. Dot size is proportional to trend magnitude.

of the rainy season. The results also show a strong drying trend for northern Central America in the last decade. From this perspective, a more detailed analysis of low-frequency variability is needed.

The ETPac has become a more active moisture supply over the last three decades. A marked increasing trend up to $10 \times 10^{-3} \mathrm{~Sv} \mathrm{yr}^{-1}$ for southernmost Central America is observed for summer and autumn (Fig. 8b). The strongest trends for moisture supply to precipitation were detected for Panama. Because contributions from the ETPac are reportedly on the increase, this result may imply an intensification for the second part of the rainy season in this area. Moreover, because the summer months were identified as seeing the minimum moisture supply (probably associated with the MSD), if the increasing trend in ETPac moisture contributions continues this could imply that midsummer dry conditions will become milder in future, in contrast to the findings of Rauscher et al. (2011). The reduction in moisture supply from the Caribbean to Guatemala and Honduras (blue circles in Fig. 8b) along with the intensification of moisture transport from the ETPac (red and magenta circles in Fig. 8b) during the second part of the rainy season is highlighted. According to these results, it can be argued that the moisture supply is contributing to the enlargement of the north-south rainfall seesaw in Central America. The detected trend also shows some similarity to the results for future climate based on IPCC models. Future climate projections suggest the drying of northern Central America, in contrast with wetter conditions for southern Central America under ENSO scenarios (e.g. Steinhoff et al., 2015). Still, at this stage, we are not able to differentiate which part of these trends are a response to natural variability and which to climate change.

Moisture transport from the GoM also exhibits an increasing trend in October. In this case, the strongest increasing trend in moisture supply was found for Guatemala (Fig. 9c). Moisture contributions from northern South America reveal an overall negative trend (Fig. 8d). Based on these results,
Panama is the country most affected by the reduction in moisture supply from this source (up to $-6 \times 10^{-3} \mathrm{~Sv} \mathrm{yr}^{-1}$ ). The detected reduction in the moisture supply accords with a decrease in the moisture availability due to the observed intensification of the hydrological cycle over the Amazon, as reported by Gloor et al. (2013). From rain gauge data, Carmona and Poveda (2015) reported an increase in rainfall in the Colombian Pacific and associated river discharges. They proposed the "rich-get-richer" mechanism as an explanation for this, in that the increasing rainfall trends detected here might be accompanied by a reduction in moisture availability for Central American transport. This shows some consistency with the decreasing trend in moisture supply from northern South America (Fig. 8d).

As previously mentioned, regardless of the fact that positive temperature trends have been detected, the results for precipitation trends lack significance. One of the main constraints in identifying trends in precipitation is the scarcity of long-term records. To determine whether moisture supply trends can be connected with significant precipitation trends, we used the CHIRPS dataset as a first attempt. CHIRPS precipitation trends were computed, and the significance of the detected trends was based on the rejection of the null hypothesis criteria under a Mann-Kendall test. The results shown in Fig. 9 show the value of the Sen's slope only where significance was reached at $90 \%$ level. Significant precipitation trends for the period 1981-2012, based on CHIRPS data, were detected mostly for the Caribbean slope of Central America. A decrease in precipitation greater than $6 \mathrm{~mm} \mathrm{month}^{-1}$ per year during the summer months was found, affecting eastern Nicaragua, Honduras and northern Costa Rica (green and blue contours in Fig. 9a). Positive trends of the same order of magnitude were detected during November for the Caribbean coast of Costa Rica and some regions of Panama (red and pink shading in Fig. 9b). Regardless of the significance of these trends, the values are in some cases negligible compared to the monthly accumulates 


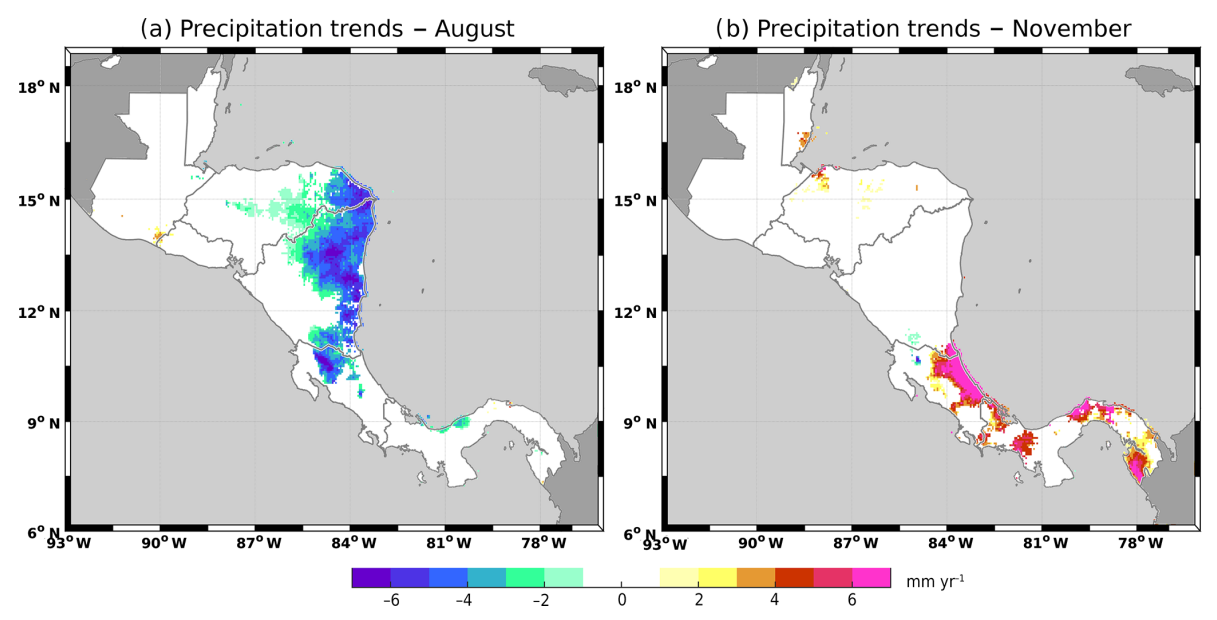

Figure 9. Long-term significant CHIRPS precipitation trends for (a) August and (b) November. Sen's slope is shown by the shading in units of millimetres per month every year. Even where significant trends were identified, these trends can be considered very small in comparison to the order of magnitude of monthly climatological values for those regions, which exceed $400 \mathrm{~mm} \mathrm{month}^{-1}$. The available data are not sufficient to explore the connection between long-term changes in moisture supply and detected rainfall trends.

for the region (greater than $400 \mathrm{~mm}$ ). There is thus no conclusive evidence to establish formal links between moisture supply and precipitation trends. In light of recent records we suggest that large-scale transport processes cannot explain changes in rainfall and that shorter-scale processes such as deep convection and transients must be taken into account in order to explain trends in precipitation. For instance, it is important to know the extent to which extreme events are changing over extended time periods. One other important aspect to consider is how the detected negative trend in moisture supply from the Caribbean to northern Central America is related to ENSO frequency.

\section{Summary}

Based on a dataset of global trajectories, it has been possible to identify moisture sources for Central American precipitation over the long term. As a contribution to an earlier analysis (Durán-Quesada et al., 2010), the present study allowed the generation of a long-term climatology of moisture sources for the region. The role of the Caribbean Sea as the main moisture supply is highlighted, and is in agreement with previous studies. Despite the fact that moisture contributions from the ETPac were confirmed to be relatively small compared to moisture exports from the Caribbean, it was determined that the seasonality of this source is a key driver of the annual cycle of precipitation. The strong link between the local excess of evaporation over precipitation, together with satellite estimates of evapotranspiration, suggests that intense moisture recycling is crucial in enhancing the first part of the rainy season. However, a detailed quantification of moisture recycling is needed to provide further evidence of the local moisture feedback. Moreover, it is important to determine the role of moisture recycling in the connection between precipitation and vegetation. This will motivate future studies of precipitation-vegetation coupling during the first part of the rainy season in the region, which could provide information on how vegetation cover and land use may have a deep impact on long-term precipitation trends.

The approach used here was found to be very useful for distinguishing the spatial scale of moisture transport, as well as for assessing the oceanic or continental origin of the moisture linked to Central American precipitation. The quantification of the moisture supply from the identified sources supports the explanation of the regional distribution of precipitation as forced by different process scales. It was determined that the first part of the rainy season is driven at a strongly local scale, while the second part of the rainy season is primarily driven by large-scale processes. The role of the regional low-level jets as moisture conveyors is remarkable, as is their influence on enhanced surface evaporation (see, e.g., Mapes et al., 2003 and Muñoz et al., 2016). From this perspective, we suggest the need to improve our understanding of the impact of regional low-level jets in modulating moisture advection within the boundary layer, as well as the impact of this on heat flux transfer.

The results from this study of the moisture supply from northern South America point to the Magdalena and Orinoco river basins as relevant moisture sources for the summer months. The analysis of OLR suggests a 2-month lag between deep convection over the north, northwest and central Amazon, and the moisture supply from northern South America. Whether Amazon convection plays a role in moisture transport through its connection with the Orinoco and Magdalena basins or by means of another mechanism is not clear. Regardless, the OLR patterns do not appear to provide sufficient evidence of a connecting bridge between Central 
American weather and climate and Amazon convection related to meridional circulation.

Shown results continuously remark the importance of the regional LLJs and the interbasin feedback to make the regional precipitation distribution that unique. Being that rainfall is perhaps the most misrepresented parameter in the models, pursuing the understanding of the CLLJ and CJ origin is fundamental for model improvement in the area. It is suggested that the CLLJ-CJ bridge should be analysed from the large-scale perspective, that is, evaluate how the ITCZ dynamics can provide information on the interaction of these two structures.

The influence of ENSO in the region must be considered carefully, despite its relatively small size, because variables such as precipitation are very complex and involve many different scales. From a broad perspective, the sources of moisture show an opposite response to warm and cold ENSO events, and the intensity of this response is sensitive to the location and origin of moisture. Oceanic sources show a larger response to ENSO compared to the continental moisture sourced identified. Positive correlations were detected between the Niño 34 index and moisture transport from the Caribbean (ETPac) during summer (winter) months. It is worth noting that a negative link was found for the Caribbean Sea transport during the spring months, while a similar response was detected during August for transport from the ETPac. The increase in summer moisture transport from the GoM to southernmost Central America was detected during warm ENSO events. ENSO forcing of continental moisture transport to Central American precipitation is mostly positive. Local contributions show a strong winter response, while for the case of northern South American transport, this relationship is mostly significant during January and February (June to August) for Nicaragua and Costa Rica (Costa Rica and Panama). It might be expected that the horizontal precipitation seesaw is reinforced, depending on the ENSO phase.

A long-term trend analysis for the moisture supply to Central American countries shows that moisture transport from the Caribbean Sea to Nicaragua and Honduras (Honduras and Guatemala) intensifies (decreases) during March (October) by $7 \times 10^{-3} \mathrm{~Sv} \mathrm{yr}^{-1}$. Results for the ETPac moisture source suggest an increase in moisture transport, mostly to southern Central America, during summer and early autumn. Significant trends of up to $10 \times 10^{-3} \mathrm{~Sv} \mathrm{yr}^{-1}$ were found for transport from this source to Panama. This result may have important implications in that it can be linked with an intensification of the Chocó Jet and further changes in the latitudinal position of the ITCZ. It was also determined that moisture transport from the Gulf of Mexico to Guatemala increases during October. It is suggested that this increase may be related to a higher frequency of cold surge activity within the GoM and a deceleration of the trade winds. It was also determined that moisture transport from northern South America to the region is decreasing, in good agreement with the reported intensification in precipitation over the Amazon Basin.

\section{Data availability}

The full dataset of global trajectories belongs to the UCRUVigo cooperation research programme and is not publicly accessible at the moment, and it also requires extremely high storage capacity. However, subsets of data such as the Central American trajectories subset used in this study can be provided for research purposes upon request. Enquiries should be sent to ana.duranquesada@ucr.ac.cr.

Competing interests. The authors declare that they have no conflict of interest.

Acknowledgements. This research was supported by UCR projects VI805B3600 and VI805B5295 in cooperation with EphysLab (UVigo). Partial funding was also provided by local grants UCR-VI-805-B0-065, A8-606, B0-130, A9-224, A7-002, 805-B6143 and 808-A9-180. Support from student E. Rodríguez (UCR) is acknowledged. Global FLEXPART simulations were computed and processed in the Tsaheva cluster from CIGEFI HPC facilities. The authors thank E. Alfaro (UCR) and H. Hidalgo (UCR) for discussions on the preliminary version of the manuscript as well as O. García (UVigo) for data retrieval support.

Edited by: S. M. Vicente Serrano

Reviewed by: three anonymous referees

\section{References}

Aguilar, E., Peterson, T. C., Obando, P. R., Frutos, R., Retana, J. A., Solera, M., Soley, J., García, I. G., Araujo, R. M., Santos, A. R., and Valle, V. E.: Changes in precipitation and temperature extremes in Central America and northern South America, 1961-2003, J. Geophys. Res.-Atmos., 110, D23107, doi:10.1029/2005JD006119, 2005.

Aide, T. M., Clark, M. L., Grau, H. R., López-Carr, D., Levy, M. A., Redo, D., Bonilla-Moheno, M., Riner, G., Andrade-Núñez, M. J., and Muñiz, M.: Deforestation and reforestation of Latin America and the Caribbean (2001-2010), Biotropica, 45, 262-271, 2013.

Alfaro, E., Pérez-Briceño, P. M., and Facio, R.: Análisis del impacto de fenómenos meteorológicos en Costa Rica, América Central, originados en los mares circundantes, Revista de Climatología, 14, 1-11, 2014.

Amador, J. A.: A climatic feature of the tropical Americas: The trade wind easterly jet, Tópicos meteorológicos y oceanográficos, 5, 91-102, 1998.

Amador, J. A.: The intra-Americas sea low-level jet, Ann. New York Acad. Sci., 1146, 153-188, 2008.

Amador, J. A., Alfaro, E. J., Lizano, O. G., and Magaña, V. O.: Atmospheric forcing of the eastern tropical Pacific: A review, Prog. Oceanogr., 69, 101-142, 2006 
Arias, G. and Calvo-Alvarado, J. C.: Water resources of the Upper Tempisque River Watershed, Costa Rica (Technical note), Tecnología en Marcha, 25, 63-70, 2012.

Arias, P. A., Martínez, J. A., and Vieira, S. C.: Moisture sources to the 2010-2012 anomalous wet season in northern South America, Clim. Dynam., 45, 2861-2884, 2015.

Brümmer, C., Black, T. A., Jassal, R. S., Grant, N. J., Spittlehouse, D. L., Chen, B., Nesic, Z., Amiro, B. D., Arain, M. A., Barr, A. G., and Bourque, C. P. A.: How climate and vegetation type influence evapotranspiration and water use efficiency in Canadian forest, peatland and grassland ecosystems, Agr. Forest Meteorol., 153, 14-30, 2012.

Carmona, A. M. and Poveda, G. E.: Prediction of mean monthly river discharges in Colombia through Empirical Mode Decomposition, Proc. IAHS, 366, 172, doi:10.5194/piahs-366-172-2015, 2015.

Chelliah, M. and Arkin, P.: Large-scale interannual variability of monthly outgoing longwave radiation anomalies over the global tropics, J. Climate, 5, 371-389, 1992.

Chikamoto, Y. and Tanimoto, Y.: Role of specific humidity anomalies in Caribbean SST response to ENSO, J. Meteorol. Soc. Jpn. Ser. II, 83, 959-975, 2005.

Dee, D. P., Uppala, S. M., Simmons, A. J., Berrisford, P., Poli, P., Kobayashi, S., Andrae, U., Balmaseda, M. A., Balsamo, G., Bauer, P., and Bechtold, P.: The ERA-Interim reanalysis: Configuration and performance of the data assimilation system, Q. J. Roy. Meteorol. Soc., 137, 553-597, 2011.

Dezzeo, N., Worbes, M., Ishii, I., and Herrera, R.: Annual tree rings revealed by radiocarbon dating in seasonally flooded forest of the Mapire River, a tributary of the lower Orinoco River, Venezuela, Plant Ecol., 168, 165-175, 2003.

Diffenbaugh, N. S. and Giorgi, F.: Climate change hotspots in the CMIP5 global climate model ensemble, Climatic Change, 114, 813-822, 2012.

Douville, H., Bielli, S., Cassou, C., Déqué, M., Hall, N. M., Tyteca, S., and Voldoire, A.: Tropical influence on boreal summer midlatitude stationary waves, Clim. Dynam., 37, 1783-1798, 2011.

Durán-Quesada, A. M.: Sources of moisture for Central America and transport based on a Lagrangian approach: variability, contributions to precipitation and transport mechanisms, $\mathrm{PhD}$ Thesis, University of Vigo, Vigo, 2012.

Durán-Quesada, A. M., Gimeno, L., Amador, J. A., and Nieto, R.: Moisture sources for Central America: Identification of moisture sources using a Lagrangian analysis technique, J. Geophys. Res.Atmos., 115, D05103, doi:10.1029/2009JD012455, 2010.

Eckhardt, S., Stohl, A., Sodemann, H., Frank, A., Seibert, P., and Wotawa, G.: The Lagrangian particle dispersion model FLEXPART version 8.0, Tech. rep., Norwegian Institude of Air Research, 2008.

Funk, C., Peterson, P., Landsfeld, M., Pedreros, D., Verdin, J., Shukla, S., Husak, G., Rowland, J., Harrison, L., Hoell, A., and Michaelsen, J.: The climate hazards infrared precipitation with stations a new environmental record for monitoring extremes, Scientific Data, 2, 150066, 2015.

Gimeno, L., Stohl, A., Trigo, R. M., Dominguez, F., Yoshimura, K., Yu, L., Drumond, A., Durán-Quesada, A. M., and Nieto, R.: Oceanic and terrestrial sources of continental precipitation, Rev. Geophys., 50, RG4003, doi:10.1029/2012RG000389, 2008.
Giorgi, F.: Climate change hot-spots, Geophys. Res. Lett., 33, 8707, doi:10.1029/2006GL025734, 2006.

Gloor, M. R. J. W., Brienen, R. J., Galbraith, D., Feldpausch, T. R., Schöngart, J., Guyot, J. L., Espinoza, J. C., Lloyd, J., and Phillips, O. L.: Intensification of the Amazon hydrological cycle over the last two decades, Geophys. Res. Lett., 40, 1729-1733, 2013.

Hidalgo, H. G., Amador, J. A., Alfaro, E. J., and Quesada, B.: Hydrological climate change projections for Central America, J. Hydrol., 495, 94-112, 2013.

Hidalgo, H. G., Durán-Quesada, A. M., Amador, J. A., and Alfaro, E. J.: The Caribbean Low-Level Jet, the Inter-Tropical Convergence Zone and Precipitation Patterns in the Intra-Americas Sea: A Proposed Dynamical Mechanism, Geograf. Ann. A, 97, 4159,2015

Huffman, G. J., Bolvin, D. T., Nelkin, E. J., Wolff, D. B., Adler, R. F., Gu, G., Hong, Y., Bowman, K. P., and Stocker, E. F.: The TRMM multisatellite precipitation analysis (TMPA): Quasiglobal, multiyear, combined-sensor precipitation estimates at fine scales, J. Hydrometeorol., 8, 38-55, 2007.

Imbach, P., Locatelli, B., Zamora, J. C., Fung, E., Calderer, L., Molina, L., and Ciais, P.: 3 Impacts of climate change on ecosystem hydrological services of Central America, in: Climate Change Impacts on Tropical Forests in Central America: An Ecosystem Service Perspective, Earthscan, p. 65, 2015.

Lachniet, M. S., Patterson, W. P., Burns, S., Asmerom, Y., and Polyak, V.: Caribbean and Pacific moisture sources on the Isthmus of Panama revealed from stalagmite and surface water $\delta^{18} \mathrm{O}$ gradients, Geophys. Res. Lett., 34, L01708, doi:10.1029/2006GL028469, 2007.

Leduc, G., Vidal, L., Tachikawa, K., Rostek, F., Sonzogni, C., Beaufort, L., and Bard, E.: Moisture transport across Central America as a positive feedback on abrupt climatic changes, Nature, 445, 908-911, 2007.

Magaña, V. O., Amador, J. A. and Medina, S.: The midsummer drought over Mexico and Central America, J. Climate, 12, 15771588, 1999.

Magaña, V. O., Vázquez, J. L., Pérez, J. L., and Pérez, J. B.: Impact of El Niño on precipitation in Mexico, Geofísica Internacional Mexico, 42, 313-330, 2003.

Maldonado, T. and Alfaro, E.: Predicción estacional para ASO de eventos extremos y días con precipitación sobre las vertientes Pacífico y Caribe de América Central, utilizando análisis de correlación canónica, InterSedes, 12, 2012.

Maldonado, T., Rutgersson, A., Amador, J., Alfaro, E., and Claremar, B.: Variability of the Caribbean low-level jet during boreal winter: large-scale forcings, Int. J. Climatol., 36, 78-108, 2015.

Mapes, B. E., Warner, T. T., Xu, M., and Negri, A. J.: Diurnal patterns of rainfall in northwestern South America. Part I: Observations and context, Mon. Weather Rev., 131, 799-812, doi:10.1175/1520-0493(2003)131<0799:DPORIN>2.0.CO;2, 2003.

Marengo, J. A., Liebmann, B., Kousky, V. E., Filizola, N. P., and Wainer, I. C.: Onset and end of the rainy season in the Brazilian Amazon Basin, J. Climate, 14, 833-852, 2001.

Meade, R. H.: Transcontinental Moving and Storage: the Orinoco and Amazon Rivers Transfer the Andes to the Atlantic, in: Large Rivers: Geomorphology and Management, edited 
by: Gupta, A., John Wiley \& Sons, Ltd, Chichester, UK, doi:10.1002/9780470723722.ch4, 2007.

Moron, V., Gouirand, I., and Taylor, M.: Weather types across the Caribbean basin and their relationship with rainfall and sea surface temperature, Clim. Dynam., 47, 601-621, 2016.

Mu, Q., Heinsch, F. A., Zhao, M., and Running, S. W.: Development of a global evapotranspiration algorithm based on MODIS and global meteorology data, Remote Sens. Environ., 111, 519-536, 2007.

Muñoz, Á. G., Díaz-Lobatón, J., Chourio, X., and Stock, M. J.: Seasonal prediction of lightning activity in North Western Venezuela: Large-scale versus local drivers, Atmos. Res., 172, 147-162, 2016.

Nakaegawa, T., Kitoh, A., Kusunoki, S., Murakami, H., and Arakawa, O.: Hydroclimate changes over Central America and the Caribbean in a global warming climate projected with $20-\mathrm{km}$ and $60-\mathrm{km}$ mesh MRI atmospheric general circulation models, Pap. Meteorol. Geophys., 65, 15, 2014.

Neelin, J. D., Münnich, M., Su, H., Meyerson, J. E., and Holloway, C. E.: Tropical drying trends in global warming models and observations, P. Natl. Acad. Sci. USA, 103, 6110-6115, 2006.

Poveda, G. and Mesa, O. J.: On the existence of Lloro (the rainiest locality on earth): enhanced ocean-land-atmosphere interaction by a low-level jet, Geophys. Res. Lett., 27, 1675-1678, 2000.

Poveda, G., Jaramillo, A., Gil, M. M., Quiceno, N., and Mantilla, R. I.: Seasonally in ENSO-related precipitation, river discharges, soil moisture, and vegetation index in Colombia, Water Resour. Res., 37, 2169-2178, 2001.

Poveda, G., Mesa, O. J., Salazar, L. F., Arias, P. A., Moreno, H. A., Vieira, S. C., Agudelo, P. A., Toro, V. G., and Alvarez, J. F.: The diurnal cycle of precipitation in the tropical Andes of Colombia, Mon. Weather Rev., 133, 228-240, 2005.

Rauscher, S. A., Giorgi, F., Diffenbaugh, N. S., and Seth, A.: Extension and Intensification of the Meso-American midsummer drought in the twenty-first century, Clim. Dynam., 31, 551-571, 2008

Rauscher, S. A., Kucharski, F., and Enfield, D. B.: The role of regional SST warming variations in the drying of Meso-America in future climate projections, J. Climate, 24, 2003-2016, 2011.

Richter, I. and Xie, S. P.: Moisture transport from the Atlantic to the Pacific basin and its response to North Atlantic cooling and global warming, Clim. Dynam., 35, 551-566, 2010.

Sáenz, F. and Durán-Quesada, A. M.: A climatology of low level wind regimes over Central America using a weather type classification approach, in: Circulation Weather types as a tool in atmospheric, climate and environmental research, Front. Earth Sci., 15, 1-18 doi:10.3389/feart.2015.00015, 2015.
Schneider, T., Bischoff, T., and Haug, G. H.: Migrations and dynamics of the intertropical convergence zone, Nature, 513, 4553, 2014.

Schulz, J., Meywerk, J., Ewald, S., and Schlüssel, P.: Evaluation of satellite-derived latent heat fluxes, J. Climate, 10, 2782-2795, 1997.

Steinhoff, D. F., Monaghan, A. J., and Clark, M. P.: Projected impact of twenty-first century ENSO changes on rainfall over Central America and northwest South America from CMIP5 AOGCMs, Clim. Dynam., 44, 1329-1349, 2015.

Stohl, A. and James, P.: A Lagrangian analysis of the atmospheric branch of the global water cycle. Part I: Method description, validation, and demonstration for the August 2002 flooding in central Europe, J. Hydrometeorol., 5, 656-678, 2004.

Taylor, M. A. and Alfaro, E. J.: Central America and the Caribbean, in: Encyclopedia of world climatology, Springer Netherlands, 183-189, 2005.

Wang, C.: Variability of the Caribbean low-level jet and its relations to climate, Clim. Dynam., 29, 411-422, 2007.

Wang, C. and Enfield, D. B.: The tropical Western Hemisphere warm pool, Geophys. Res. Lett., 28, 1635-1638, 2001.

Wang, C., Zhang, L., and Lee, S. K.: Response of freshwater flux and sea surface salinity to variability of the Atlantic warm pool, J. Climate, 26, 1249-1267, 2013.

Wolter, K. and Timlin, M. S.: Measuring the strength of ENSO events: how does 1997/98 rank?, Weather, 53, 315-324, doi:10.1002/j.1477-8696.1998.tb06408.x, 1998.

Xu, H., Xie, S. P., Wang, Y., and Small, R. J.: Effects of Central American Mountains on the Eastern Pacific Winter ITCZ and Moisture Transport, J. Climate, 18, 3856-3873, 2005.

Zárate, E.: Climatología de masas invernales de aire frío que alcanzan Centroamérica y el Caribe y su relación con algunos Índices Árticos. Tópicos Meteorológicos y Oceanográficos, 12, 35-55, 2013.

Zhang, C., McGauley, M., and Bond, N. A.: Shallow meridional circulation in the tropical eastern Pacific, J. Climate, 17, 133139, 2004.

Zuluaga, M. D. and Houze Jr., R. A.: Extreme convection of the near-equatorial Americas, Africa, and adjoining oceans as seen by TRMM, Mon. Weather Rev., 143, 298-316, 2015.

Zuluaga Arias, M. D. and Poveda Jaramillo, G.: Diagnóstico de sistemas convectivos de mesoescala sobre Colombia y el océano Pacífico Oriental durante 1998-2002, Avances en Recursos Hidraulicos, 11, 145-160, 2004. 